\title{
Phytochemical analysis of methanolic extract of Ulva rigida C.Ag. collected from Koothankuzhi Coast, Tirunelveli district, Tamil Nadu, India
}

\author{
1Dr. M. Muthu Sheeba, ${ }^{2}$ Dr. J. John Peter Paul*, ${ }^{3}$ Dr. C. Iniya Udhaya \\ 1Centre for Advanced Research in Plant Sciences (CARPS), Department of Botany, St. Xavier's College (Autonomous), Palayamkottai - 627 \\ 002, Tamil Nadu, India \\ 2*Assistant Professor of Botany and Director, Centre for Advanced Research in Plant Sciences (CARPS), St. Xavier's College (Autonomous), \\ Palayamkottai - 627 002, Tamil Nadu, India \\ ${ }^{3}$ Assistant Professor of Botany, Sri Kaliswari College (Autonomous), Sivakasi - 626 123, Tamil Nadu, India
}

\begin{abstract}
The present study was concentrated to explore the phytochemicals present in the methanolic extract of Ulva rigida C.Ag., collected from Koothankuzhi in the south east coast of Tamil Nadu, India. The phytochemical analysis of methanolic extract was screened using the standard procedure for UV-Visible spectroscopic, HPLC and FTIR. The UV-Visible spectrum showed the compounds separated at the nm of $662,603,533$ and 400 with the absorption $0.653,0.331,0.458$ and 2.684 respectively. The qualitative HPLC fingerprint profile displayed fourteen compounds at different retention time of $1.770 \mathrm{~min}, 2.230 \mathrm{~min}, 2.540 \mathrm{~min}, 2.870 \mathrm{~min}, 3.090 \mathrm{~min}, 3.377 \mathrm{~min}, 3.900 \mathrm{~min}, 4.257 \mathrm{~min}$, $4.797 \mathrm{~min}, 5.340 \mathrm{~min}, 5.853 \mathrm{~min}, 6.520 \mathrm{~min}, 7.730 \mathrm{~min}$ and $9.220 \mathrm{~min}$. The result of FTIR analysis was found the presence of functional groups such as alkynes, sulfonic acids, carboxylic acids, carboxylic acid salt, aldehydes, aliphatic and unsaturated hydrocarbons.
\end{abstract}

Keywords: Ulva rigida, UV-Visible, HPLC, FTIR

Article Info: Received 18 Oct 2018; Review Completed 27 Nov 2018; $\quad$ Accepted 29 Nov 2018; Available online 15 Dec 2018

\section{Cite this article as:}

Muthu Sheeba M, John Peter Paul J, Iniya Udhaya C, Phytochemical analysis of methanolic extract of Ulva rigida C.Ag. collected from Koothankuzhi Coast, Tirunelveli district, Tamil Nadu, India, Journal of Drug Delivery and Therapeutics. 2018; 8(6-s):94-96 DOI: http://dx.doi.org/10.22270/jddt.v8i6-s.2091

*Address for Correspondence:

Dr. John Peter Paul J., Research Department of Botany, St. Xavier's College (Autonomous), Palayamkottai - 627 002, Tamil Nadu, India.

\section{INTRODUCTION}

Seaweeds constitute one of the important living resources categorized under three groups namely Chlorophyceae (green algae), Phaeophyceae (brown algae) and Rhodophyceae (red algae). There are about 900 species of green seaweeds, 1500 brown seaweeds and 4000 red seaweeds in nature. The greatest variety of red seaweeds is present in subtropical and tropical waters, while brown seaweeds and green seaweeds are more commonly found in cooler and temperate waters respectively ${ }^{1}$. As seaweeds are important renewable resources in the marine ecosystem and have been a part of human civilization from time immemorial. The long history of seaweeds utilization for a various purposes has led to the regular realization that some of the compounds are more superior and valuable in comparison to the counterparts of land plants ${ }^{2}$.

Seaweeds produce an extensive variety of chemicals, some of the chemicals stand only as natural resources 3 . Seaweeds are the marine macro algae found in the shallow waters of sea, estuaries and backwaters. Earlier reports on the uses of seaweeds have been noticed early as 2500 years ago in Chinese literature also ${ }^{4}$. Seaweeds are considered as source of bioactive compounds and create a great variety of secondary metabolites characterized by a broad spectrum of biological activities 5. There are various reports of compounds derived from seaweeds with a broad range of biological activities such as antibiotics, antiviral diseases, anti-tumour and anti-inflammatory as well as neurotoxins 6. Hence the present study was carried out to screen the phytochemicals in Ulva rigida C.Ag., collected from Koothankuzhi coast, Tirunelveli district in the south east coast of Tamil Nadu, India.

\section{MATERIALS AND METHODS}

\section{Collection of Plant sample}

The plant materials used in the present study was Ulva rigida C.Ag., belonging to Chlorophyceae (green algae) was made during the low tidal and subtidal regions (up to $1 \mathrm{~m}$ depth) by hand picking. The collected materials were washed thoroughly with marine water in the field itself to remove the epiphytes and sediment particles. Then the samples were packed separately in polythene bags in wet 
conditions and brought to the laboratory, then thoroughly washed in tap water followed by distilled water to remove the salt on the surface of the thalli. They were stored in 5\% formalin solution 7 .

\section{Preparation of extracts}

For the preparation of methanolic extract, the plant specimens were washed thoroughly and placed on blotting paper and spread out at room temperature in the shade condition for drying. The shade dried samples were grounded to fine powder using a tissue blender. The powdered samples were then stored in the refrigerator for further use. $30 \mathrm{~g}$ powdered samples were packed in Soxhlet apparatus and extracted with methanol for $8 \mathrm{~h}$ separately ${ }^{8}$.

\section{UV-Vis spectral analysis}

The methanolic crude extract containing the bioactive compound was analyzed UV-Visible spectroscopically for further confirmation. The methanolic crude extract of Ulva rigida C.Ag. was scanned in a wavelength ranging from 200-900nm using a Shimazdu spectrophotometer and characteristic peaks were detected 9

\section{HPLC Analysis}

The HPLC method was performed on a Shimadzu LC-10AT VP HPLC system, equipped with a model LC-10AT pump, UV-Vis detector SPD-10AT, a Rheodyne injector fitted with a $20 \mu$ l loop and an auto injector SIL-10AT. A Hypersil ${ }^{\circledR}$ BDS C-18 column $(4.6 \times 250 \mathrm{~mm}, 5 \mu \mathrm{m}$ size $)$ with a C-18 guard column was used. The elution was carried out with gradient solvent systems with a flow rate of $1 \mathrm{ml} / \mathrm{min}$ at ambient temperature $\left(25-28^{\circ} \mathrm{C}\right)$. The mobile phase consisted of $0.1 \% \mathrm{v} / \mathrm{v}$ methanol (solvent A) and water (solvent B). The mobile phase was prepared daily, filtered through a $0.45 \mu \mathrm{m}$ and sonicated before use. Total running time was $15 \mathrm{~min}$. The sample injection volume was $20 \mu \mathrm{l}$ while the wavelength of the UV-Vis detector was set at $254 \mathrm{~nm}^{10}$.

\section{Instrumentation}

An isocratic HPLC (Shimadzu HPLC Class VP series) with two LC- 0 AT VP pumps (Shimadzu), a variable wave length programmable photo diode array detector SPD-M10A VP (Shimadzu), a CTO- 10AS VP column oven (Shimadzu), a SCL-10A VP system controller (Shimadzu), a reverse phase Luna $5 \mu \mathrm{l} \mathrm{C18} \mathrm{(2)} \mathrm{and} \mathrm{Phenomenex} \mathrm{column} \mathrm{(250} \mathrm{mm} \mathrm{X}$ $4.6 \mathrm{~mm}$ ) were used. The mobile phase components methanol: water $455: 55)$ were filtered through a $0.2 \mu$ membrane filter before use and were pumped from the solvent reservoir at a flow rate of $1 \mathrm{ml} / \mathrm{min}$ which yielded column backup pressure of $260-270 \mathrm{kgf} / \mathrm{cm}^{2}$. The column temperature was maintained at $27^{\circ} \mathrm{C} .20 \mu \mathrm{l}$ of the respective sample and was injected by using a Rheodyne syringe (Model 7202, Hamilton).

\section{FTIR analysis}

The methanolic extract of Ulva rigida C.Ag. was shade dried and FTIR analysis was performed using Perkin Elmer Spectrophotometer system, which was used to detect the characteristic peaks and their functional groups. The peak values of the FTIR were recorded. Each and every analysis was repeated twice and confirmed the spectrum ${ }^{11}$.

\section{RESULTS AND DISCUSSION}

\section{UV-Visible spectrum analysis}

The UV-Visible spectrum of the methanolic extract of Ulva rigida C.Ag. was selected at the wavelength of $200 \mathrm{~nm}$ to $900 \mathrm{~nm}$ due to the sharpness of the peaks and proper baseline. The profile showed the compounds separated at the nm of $662,603,533$ and 400 with the absorption 0.653 , $0.331,0.458$ and 2.684 respectively (Figure-1).

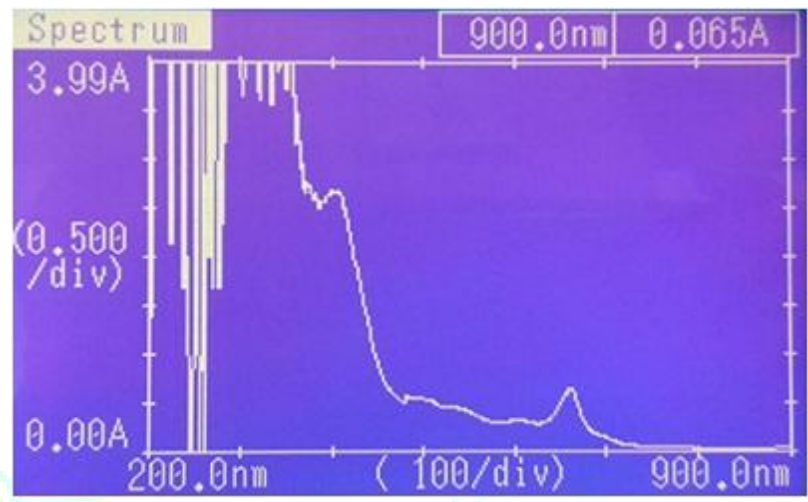

Figure 1: UV-Visible spectrum of methanolic extract of Ulva rigida C.Ag.

\section{HPLC analysis}

The qualitative HPLC fingerprint profile of the methanolic extract of Ulva rigida C.Ag. was selected at a wavelength of $660 \mathrm{~nm}$ due to the sharpness of the peaks and proper baseline. The methanolic extract prepared by hot extraction was subjected to HPLC for the separation and identification of constituents present in the Ulva rigida C.Ag. Fourteen compounds were separated from the methanolic extract of Ulva rigida C.Ag. at different retention time of $1.770 \mathrm{~min}, 2.230 \mathrm{~min}, 2.540 \mathrm{~min}, 2.870 \mathrm{~min}$, $3.090 \mathrm{~min}, 3.377 \mathrm{~min}, 3.900 \mathrm{~min}, 4.257 \mathrm{~min}, 4.797 \mathrm{~min}$, $5.340 \mathrm{~min}, 5.853 \mathrm{~min}, 6.520 \mathrm{~min}, 7.730 \mathrm{~min}$ and $9.220 \mathrm{~min}$. The profile displayed nine prominent peaks at the retention time of $1.770 \mathrm{~min}, 2.230 \mathrm{~min}, 2.540 \mathrm{~min}, 2.870 \mathrm{~min}$, $3.090 \mathrm{~min}, 3.377 \mathrm{~min}, 5.340 \mathrm{~min}, 6.520 \mathrm{~min}$ and $9.220 \mathrm{~min}$ followed by seven moderate peaks were observed at the retention time of $3.900 \mathrm{~min}, 4.257 \mathrm{~min}, 4.797 \mathrm{~min}, 5.853 \mathrm{~min}$ and 7.730min (Figure-2).

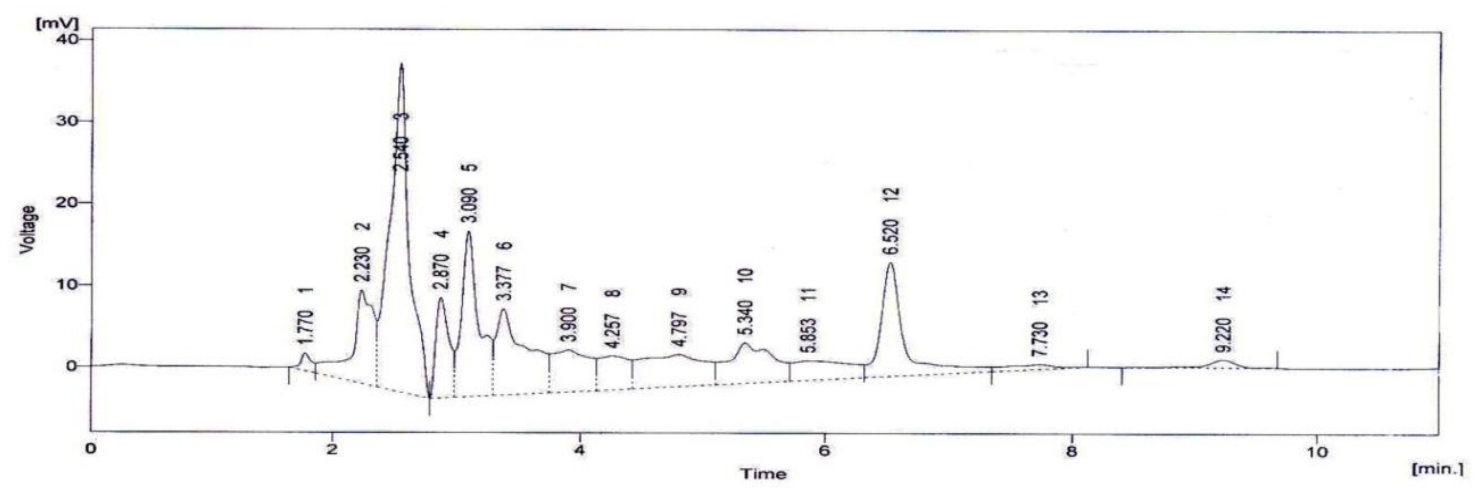

Figure 2: HPLC analysis of methanolic extract of Ulva rigida C.Ag. 


\section{FTIR analysis}

The FTIR spectrum was used to predict the functional group of the active components based on the peak value in the region of infra red radiation. The crude methanolic extract of Ulva rigida C.Ag. was conceded into the FTIR and the functional groups of the components were separated based on its peak ratio. FTIR spectrum of methanolic extract showed different peaks at 680.83, 1166.85, $1461.94,1598.88,1739.67,2854.45$ and $2925.81 \mathrm{~cm}^{-1}$. It was confirmed the presence of functional groups such as alkynes $\left(\mathrm{C}=\mathrm{C}-\mathrm{H}\right.$ bending), sulfonic acids $\mathrm{SO}_{3}$ sym stretching), carboxylic acids ( $\mathrm{OH}$ bending), carboxylic acid salt (COO- antisym stretching), aldehydes ( $\mathrm{C}=0$ stretching), aliphatic ( $\mathrm{CH}$ antisym and sym stretching) and unsaturated hydrocarbons (=C-H stretching) respectively (Figure-3).

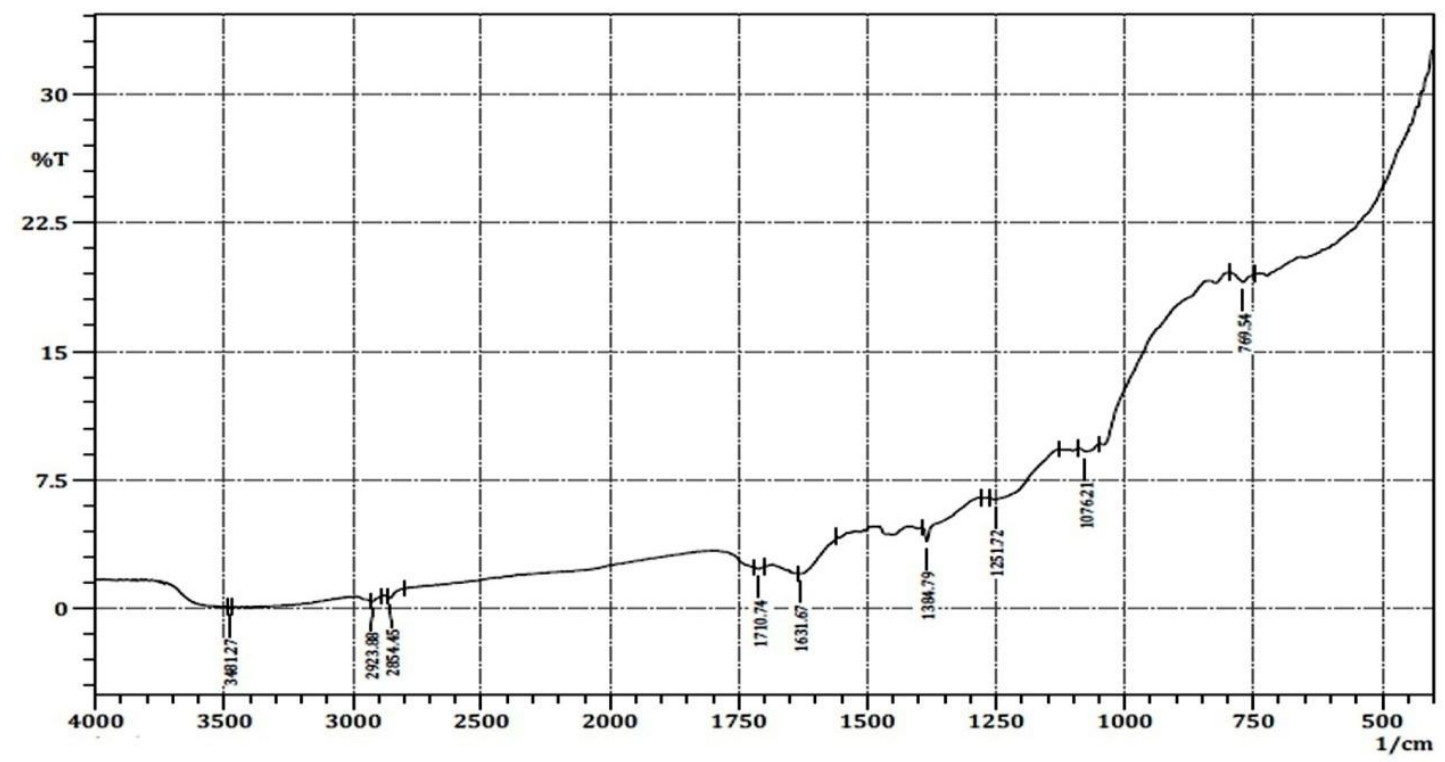

Figure 3: FT-IR spectrum of methanol extract of Ulva rigida C.Ag.

\section{CONCLUSION}

From the present study, it was noted that UV-Visible spectrum of methanolic extract of Ulva rigida C.Ag. showed the compounds separated at the nm of $662,603,533$ and 400 with the absorption $0.653,0.331,0.458$ and 2.684 respectively. The qualitative HPLC fingerprint profile displayed fourteen compounds at different retention time of $1.770 \mathrm{~min}, 2.230 \mathrm{~min}, 2.540 \mathrm{~min}, 2.870 \mathrm{~min}, 3.090 \mathrm{~min}$ $3.377 \mathrm{~min}, 3.900 \mathrm{~min}, 4.257 \mathrm{~min}, 4.797 \mathrm{~min}, 5.340 \mathrm{~min}$, $5.853 \mathrm{~min}, 6.520 \mathrm{~min}, 7.730 \mathrm{~min}$ and $9.220 \mathrm{~min}$. The result of FTIR analysis was found the presence of functional groups such as alkynes, sulfonic acids, carboxylic acids, carboxylic acid salt, aldehydes, aliphatic and unsaturated hydrocarbons in the methanolic extract of Ulva rigida C.Ag.

\section{CONFLICT OF INTEREST}

The author declares that he has no conflict of interest.

\section{REFERENCES}

1. Dowes CJ, Marine Botany. John Wiley and Sons, New York, 1981.

2. John Peter Paul J, Screening of preliminary phytochemicals of Caulerpa racemosa (Forssk.) Web. V. Bosse from Idinthakarai, Tirunelveli District, Tamil Nadu, India. Indo American Journal of Pharmaceutical Sciences, 2018; 5(6):5463-5466.

3. McHugh DJ, A guide to the seaweed industry. FAO fisheries Technical Paper, 2003; 441:105.
4. Tseng CK, The past, present and future of phycology in China. Hydrobiologia, 2004; 512:11-20.

5. Trono JGC, Diversity of the seaweed flora of the Philippines and its utilization. Hydrobiologia, 1999; 398/399:1-6.

6. Scheuer PJ, Some marine ecological phenomena: chemical basis and biomedical potential. Science, 1900; 248:173-177.

7. Iniya Udhaya C, John Peter Paul J, Screening of preliminary phytochemicals of Gracilaria cylindrica Boergesen in Koothankuzhi, Tirunelveli district, Tamil Nadu, India. Indo American Journal of Pharmaceutical Sciences, 2017; 4(12):4590-4594.

8. Iniya Udhaya C, John Peter Paul J, Screening of anti-oxidant activity of methanolic extract of Gracilaria fergusonii J.Ag. (Red seaweed) in Hare Island, Thoothukudi, Tamil Nadu, India. Indo American Journal of Pharmaceutical Sciences, 2017; 4(9):2724-2727.

9. Amster Regin Lawrence R, Iniya Udhaya C, John Peter Paul J, Phytochemical analysis of chloroform extract of Sargassum linearifolium (Turner) C.Ag. (Brown seaweed) using UV-VIS, FTIR and HPLC. Indo American Journal of Pharmaceutical Research, 2017; 7(9):390-395.

10. John Peter Paul J, Shri Devi SDK, Phytochemical studies on Padina pavonica (L.) Thivy ex Taylor. Indo American Journal of Pharmaceutical Research, 2013; 3(6):4452-4459.

11. John Peter Paul J, Phytochemical analysis of methanolic extract of Caulerpa scalpelliformis (R.Br.) Web. V. Bosse collected from Hare Island, Thoothukudi, Tamil Nadu, India. Indo American Journal of Pharmaceutical Sciences, 2018; 5(3):1905-1908. 